\title{
PERBANDINGAN INKLINASI DAN UKURAN RAHANG ANTARA ORANG JAWA BUTA DAN NORMAL
}

\author{
Christnawati \\ Bagian Ortodonsia Fakultas Kedokteran Gigi, Universitas Gadjah Mada Yogyakarta
}

\begin{abstract}
ABSTRAK
Latar Belakang. Penglihatan merupakan salah satu faktor yang diperlukan untuk mengontrol postur kepala. Postur kepala berhubungan dengan kompleks kraniofasial. Maksila dan mandibula merupakan bagian dari kompleks kraniofasial. Pada orang buta terjadi penyimpangan pertumbuhan dan perkembangan daerah orbita karena tidak adanya rangsang. Tujuan penelitian adalah untuk mempelajari perbandingan inklinasi dan ukuran rahang berdasarkan jenis kelamin antara orang Jawa buta dan normal. Metode Penelitian Penelitian ini dilakukan terhadap 53 subjek, terdiri dari 25 orang buta (12 orang laki-laki dan 13 orang perempuan) dan 28 orang normal (14 orang laki-laki dan 14 orang perempuan). Setiap subjek penelitian dilakukan pengambilan sefalogram lateral pada posisi alamiah kepala, kemudian dilakukan penapakan pada kertas kalkir di atas iluminator. Pengukuran sembilan parameter inklinasi dan ukuran maksila dan mandibula dilakukan pada hasil penapakan. Data dianalisis dengan uji Anava dua jalur. Hasil penelitian menunjukkan bahwa terdapat perbedaan yang tidak bermakna $(p<0,05)$ pada inklinasi maksila, inklinasi mandibula, panjang basis maksila, dan bentuk mandibula antara orang buta dan normal Jawa serta antara jenis kelamin. Ukuran maksila laki-laki buta lebih besar daripada perempuan normal $(p<0,05)$. Panjang mandibula dan panjang basis mandibula laki-laki normal lebih besar daripada perempuan normal dan kelompok buta, serta perempuan normal lebih besar daripada perempuan buta $(p<0,05)$. Kesimpulan Ukuran maksila laki-laki buta lebih besar daripada perempuan normal. Panjang mandibula dan panjang basis mandibula laki-laki normal lebih besar daripada perempuan normal, laki-laki buta, dan perempuan buta, serta perempuan normal lebih besar daripada perempuan buta. Maj Ked Gi; Desember 2011; 18(2): 133-136
\end{abstract}

Kata kunci: kebutaan, inklinasi maksila, inklinasi mandibula, ukuran maksila, ukuran mandibula

\begin{abstract}
Background Vision is one of the factors involved in the control of head posture. The posture of the head is related to craniofacial complex. Maxilla and mandible are part of craniofacial complex. In the blind there are deviations of growth and development of the orbital region in the absence of stimuli. The purpose of this study was to compare the inclinations and sizes of maxilla and mandible of the blind and normal Javanese subjects. Methods The research was conducted on 53 subjects, consisting of 25 blind subjects (12 men and 13 women) and 28 normal subjects (14 men and 14 women). Each subject of the research conducted on the lateral sefalogram in natural head position, then trace on tracing paper over the illuminator. In the nine-parameter measurements performed tracing inclination and size of the maxilla and mandible. Data were analyzed with two way ANOVA. The results showed that there were no significant differences $(p<0.05)$ on the inclination of the maxillary, mandibular inclination, maxillary base length, and shape of the mandible between the blind and normal Java as well as between the sexes. The size of the blind males maxilla larger than normal famales $(p<0.05)$. The length of the mandible and the mandibular base length of the normal males larger than normal and the blind females, as well as normal females is greater than the blind females $(p<0.05)$. The conclusion The size of the maxilla of the blind males larger than normal females. The length of the mandible and the mandibular base length of the normal males larger than normal females, the blind males, and the blind females, as well as normal females is greater than the blind females. Maj Ked Gi; Desember 2011; 18(2): 133-136
\end{abstract}

Keywords: blindness, maxillary inclination, mandibulary inclination, maxillary size, mandibulary size

\section{PENDAHULUAN}

Indera penglihatan berfungsi untuk menerima informasi melalui rangsang cahaya dan memegang peranan $80 \%$ - $85 \%$ dari seluruh persepsi keinderaan manusia'. Tunanetra adalah kerusakan struktur dan atau fungsi mata atau indera penglihatan, sedangkan buta merupakan klasifikasi ketunanetraan yang paling berat, yaitu ketidak mampuan menggunakan indera penglihatan dengan sempurna².

Postur tubuh orang buta cenderung anomali, karena orang buta mempunyai kerusakan atau penyimpangan gambaran tubuh dan persepsi vertikal yang tidak tepat ${ }^{3,4}$. Adaptasi postural memerlukan perubahan aktivitas otot, jika dipertahankan dalam waktu yang cukup lama selama masa pertumbuhan akan menyebabkan perubahan relasi muskuloskeletal. Keadaan ini akhirnya menjadi penyebab perubahan keadaan normal menjadi morfologi baru tulang kraniofasial dan dentoalveolar ${ }^{4}$. Postur kepala orang buta lebih ke depan bawah dibandingkan dengan postur kepala orang normal ${ }^{4-6}$.

Beberapa peneliti mengatakan bahwa terdapat hubungan yang erat antara postur kepala dan leher dan morfologi kraniofasial dan dentoalveolar. Dikemukakan bahwa posisi alamiah kepala mempengaruhi orientasi basis kranial dan mempengaruhi terjadinya maloklusi Kelas II dan III. Dikemukakan 
bahwa perkembangan maloklusi Kelas II dengan hiperekstensi kepala terhadap kolumna servikal selama tidur. Perkembangan vertikal muka dan prevalensi maloklusi Kelas II lebih besar pada subjek dengan postur kepala jelek. Terangkatnya posisi kepala dan retrognatisme muka terjadi pada subjek dengan sudut basis kranial datar ${ }^{8}$.

Posisi alamiah kepala juga dikaitkan dengan prognatisme maksila. Postur kepala akan mempengaruhi morfologi kraniofasial dan dentoalveolar, antara lain: mempengaruhi tinggi dentoalveolar anterior, inklinasi bidang oklusal pada kasus dengan defisiensi keseimbangan dentoalveolar dan overbite, mempengaruhi posisi mandibula, mempengaruhi hubungan vertikal rahang, sudut mandibular, dan inklinasi gigi insisif bawah ${ }^{9-12}$.

Orang Jawa termasuk suku fisik DeuteroMelayu $^{13}$. Dikemukakan bahwa perbedaan kelompok etnik manusia mempunyai kecenderungan memperlihatkan pola bentuk tengkorak dan rahang, meskipun pola tersebut sering tidak terlihat karena adanya variasi individual ${ }^{14}$. Jenis ras memperlihatkan variasi yang lebih besar daripada jenis kelamin ${ }^{15}$. Dikatakan bahwa pengukuran angular antara orang laki-laki dan perempuan tidak menunjukkan perbedaan, sedangkan pada pengukuran liniar menunjukkan adanya perbedaan ${ }^{4,5}$.

Penelitian ini bertujuan untuk mempelajari perbandingan inklinasi dan ukuran rahang antara orang Jawa buta dan normal, serta mempelajari perbandingan inklinasi dan ukuran rahang antara lakilaki dan perempuan Jawa, sehingga hasil penelitian yang diperoleh dapat menjadi bahan pertimbangan dalam menentukan perawatan ortodontik orang Jawa buta.

\section{METODE PENELITIAN}

Populasi orang Jawa buta diperoleh di Sasana Rehabilitasi Penderita Cacat Netra (SRPCN) Sewon Bantul dan di Yayasan Kesejahteraan Tunanetra Islam (Yaketunis) Yogyakarta, dengan kriteria: menderita buta sejak lahir, keturunan Jawa dua generasi di atasnya, umur 20-25 tahun, gigi-gigi lengkap dari gigi molar kedua kanan hingga gigi molar kedua kiri, relasi gigi molar pertama Kelas I Angle, belum pernah dan tidak sedang menjalani perawatan ortodontik. Populasi orang Jawa normal adalah mahasiswa Fakultas Kedokteran Gigi Universitas Gadjah Mada Yogyakarta angkatan tahun 2006-2007, dengan kriteria: berpenglihatan normal dan tidak berkaca mata, keturunan Jawa dua generasi di atasnya, umur 20-25 tahun, gigi-gigi lengkap dari gigi molar kedua kanan hingga gigi molar kedua kiri, relasi gigi molar pertama Kelas I Angle, belum pernah dan tidak sedang menjalani perawatan ortodontik. Kriteria eksklusif subjek penelitian adalah: 1). Subjek yang tidak memenuhi kriteria inklusif; 2). Subjek menolak berpartisipasi setelah penjelasan (informed consent). Semua anggota populasi dijadikan sampel.

Pengambilan sefalogram lateral dengan posisi alamiah kepala dilakukan pada masing-masing subjek penelitian. Penentuan posisi alamiah kepala adalah dengan menggerak-gerakkan kepala ke depan dan belakang hingga dicapai posisi keseimbangan kepala yang paling enak. Gigi-gigi dalam keadaan oklusi sentrik. Pengambilan sefalogram dilakukan di Bagian Radiologi Rumah Sakit Gigi dan Mulut Fakultas Kedokteran Gigi Universitas Gadjah mada oleh seorang tenaga pelaksana yang telah diberi instruksi terlebih dahulu.

Penapakan sefalogram dilakukan di atas iluminator dengan sinar dingin pada kertas asetat.

Pengukuran sembilan variabel maksila dan mandibula dilakukan pada masing-masing hasil penapakan. Variabel inklinasi maksila adalah NSL NL (sudut antara garis sela tursika-nasion dan garis nasal), inklinasi mandibula meliputi NSL/ML (sudut antara garis sela tursika-nasion dan garis mandibula), NSL/RL (sudut antara garis sela tursika-nasion dan garis ramus), dan NL/RL (sudut antara garis nasal dan garis ramus). Variabel ukuran maksila adalah ss-pm (jarak subspinal-pterigomaksilaris) dan sppm (jarak spinal-pterigomaksilaris), variabel ukuran mandibula meliputi pgn-cd (jarak prognation-kondilion), pg-tgo (pogonion-titik perpotongan ML dan RL), dan ML/RL (sudut antara garis mandibula dan garis ramus) (Gambar).

Uji anava dua jalur dengan tingkat kepercayaan $95 \%$ digunakan untuk mengetahui ada tidaknya perbedaan masing-masing rerata. Seluruh perhitungan statistik dalam analisis data menggunakan program SPSS versi 16 .

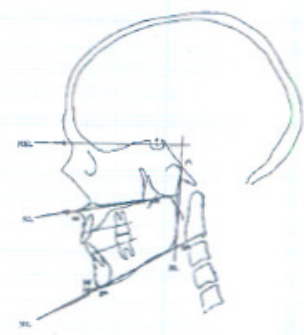

Gambar 1: Variabel inklinasi maksila (NSL/NL), inklinasi mandibula (NSL/ML, NSL/RL, dan NL/RL), ukuran maksila (ss-pm dan sp-pm), ukuran mandibula (pgncd, pg-tgo, dan ML/RL) (Solow dan Tallgren, 1976)

\section{HASIL DAN PEMBAHASAN}

\section{HASIL PENELITIAN}

Rerata, simpangan baku, uji Anova dua jalur, dan LSD sembilan variabel penelitian dan untuk 
mengetahui adanya perbedaan antara kelompok buta dan kelompok normal serta antara jenis kelamin disajikan pada tabel 1 dan 2.

Tabel 1. Rerata, simpangan baku, dan uji ANOVA dua jalur variabel NSL/NL, NSL/ML, NSL RL, NL/R, ss-pm, sp-pm, pgn-cd, pg-tgo, dan ML/RL kelompok buta laki-laki dan perempuan, kelompok normal laki-laki dan perempuan.

\begin{tabular}{|c|c|c|c|c|c|c|}
\hline \multirow{3}{*}{ no } & \multirow{3}{*}{ variabel } & \multicolumn{4}{|c|}{ Kelompok } & \multirow{3}{*}{ Sig. } \\
\hline & & \multicolumn{2}{|c|}{ buta } & \multicolumn{2}{|c|}{ nomal } & \\
\hline & & lakilaki & perempuan & lakitaki & peremouan & \\
\hline 1 & NSLNL & $6,958 \pm 4,678$ & $9,807 \pm 3,288$ & $7,821 \pm 2,997$ & $9,642 \pm 2,957$ & 0,121 \\
\hline 2 & NSLML & $29,291 \pm 7.390$ & $28,246 \pm 10,238$ & $29,107 \pm 5,893$ & $33,714 \pm 5,124$ & 0,217 \\
\hline 3 & NSURL & $86,750 \pm 6,347$ & $88,076 \pm 5,126$ & $87,750 \pm 6,540$ & $88,392 \pm 4,776$ & 0,899 \\
\hline 4 & NLRL & $79,916 \pm 9,044$ & $77,115 \pm 4,103$ & $79,821 \pm 6,446$ & $79,107 \pm 5,284$ & 0,660 \\
\hline 5 & ss-pm & $50,021 \pm 3,175$ & $47,571 \pm 3,853$ & $51,425+2,424$ & $48,338+2,845$ & $0,015^{\prime \prime}$ \\
\hline 6 & $\mathrm{sp} \cdot \mathrm{pm}$ & $53,485+2,891$ & $50,878 \pm 4,579$ & $54,516 \pm 3,985$ & $53,123 \pm 3,187$ & 0,093 \\
\hline 7 & $\operatorname{pgn}-c d$ & $122,966 \pm 6,671$ & $120,484 \pm 5,208$ & $129,550 \pm 6,855$ & $123,614 \pm 4,675$ & $0,002^{*+}$ \\
\hline 8 & $\mathrm{pg}-\operatorname{tg} 0$ & $77,091 \pm 5,994$ & $75,869 \pm 4,459$ & $84,350 \pm 4,701$ & $80,041 \pm 2,722$ & $0,000^{* *}$ \\
\hline 9 & MLRL & $124,000 \pm 8,676$ & $125,153 \pm 11,027$ & $122,035 \pm 10,023$ & $125,571 \pm 4,933$ & 0,729 \\
\hline \multicolumn{3}{|c|}{$\begin{array}{l}\text { NSL/NL } \\
\text { NSL/ML, NSL/RL, NL/RL } \\
\text { ss-pm, sp-pm } \\
\text { pgn-cd, pg-tgo,ML/RL. }\end{array}$} & \multicolumn{3}{|c|}{$\begin{array}{l}\text { : inklinasi maksila } \\
\text { : inklinasi mandibula } \\
\text { : ukuran maksila } \\
\text { : ukuran mandibula }\end{array}$} & \\
\hline
\end{tabular}

Tabel 2. Rangkuman uji LSD variabel NSL/NL, NSL/ML, NSL/RL, NL/R, ss-pm, sp-pm, pgn-cd, pg-tgo, dan ML/RL kelompok buta laki-laki dan perempuan, kelompok normal laki-laki dan perempuan.

\begin{tabular}{|c|c|c|c|c|c|c|c|c|c|c|}
\hline & & $\begin{array}{l}\text { NSU } \\
\text { NLL }\end{array}$ & $\begin{array}{l}\text { NSU } \\
\text { ML }\end{array}$ & $\begin{array}{c}\text { NSU } \\
\text { RL }\end{array}$ & NURL & $\begin{array}{l}\text { ss- } \\
\text { pm }\end{array}$ & $\begin{array}{l}\text { sp- } \\
\text { pm }\end{array}$ & $\begin{array}{c}\mathrm{pgn}- \\
\mathrm{cd}\end{array}$ & $\begin{array}{l}\text { pg. } \\
\text { tgo }\end{array}$ & $\begin{array}{l}\text { MU } \\
\text { RL }\end{array}$ \\
\hline \multirow{3}{*}{$\begin{array}{l}\frac{\bar{v}}{0} \\
\frac{1}{x} \\
\text { g }\end{array}$} & $\begin{array}{l}\text { Lakilaki } \\
\text { normal }\end{array}$ & 0.534 & 0,949 & 0,658 & 0,970 & 0,263 & 0,484 & $0,007^{m}$ & $0,000^{\circ \prime}$ & 0,579 \\
\hline & $\begin{array}{l}\text { Perempuan } \\
\text { nomal }\end{array}$ & 0,057 & 0,133 & 0,468 & 0,749 & $0,000^{\circ}$ & $0015^{-}$ & 0,782 & 0,109 & 0,657 \\
\hline & $\begin{array}{l}\text { Perempuan } \\
\text { buta }\end{array}$ & 0,058 & 0,724 & 0,564 & 0.274 & $0.010^{-}$ & 0,354 & 0.299 & 0,506 & 0,748 \\
\hline \multirow{2}{*}{ 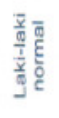 } & $\begin{array}{l}\text { Perempuan } \\
\text { normal }\end{array}$ & 0,175 & 0,104 & 0,767 & 0,769 & $0,045^{\prime \prime}$ & 0,070 & $0,011^{\prime \prime}$ & $0,015^{\prime \prime}$ & 0,300 \\
\hline & $\begin{array}{l}\text { Perempuan } \\
\text { buta }\end{array}$ & 0,147 & 0,763 & 0,862 & 0,277 & 0,172 & 0,801 & $0.000^{\prime \prime}$ & $0,000^{\prime \prime}$ & 0,369 \\
\hline$\frac{5}{6}$ & $\begin{array}{l}\text { Perempuan } \\
\text { nomal }\end{array}$ & 0,903 & 0,069 & 0.896 & 0,423 & 0,530 & 0,124 & 0,175 & 0,002 & 0,904 \\
\hline
\end{tabular}

\section{PEMBAHASAN}

Keterbatasan jenis dan jumlah pengalaman, keterbatasan aktivitas fisik, keterbatasan hubungan dengan lingkungan dan adanya adatan pada orang buta, akan menyebabkan perubahan postur kepala. Perubahan postur kepala akan mengakibatkan perubahan aktivitas otot, jika perubahan-perubahan ini berlangsung lama selama masa pertumbuhan maka akan menyebabkan perubahan muskuloskeletal. Ber- dasarkan hal tersebut di atas, maka dalam pemilihan subjek penelitian orang buta dipilih orang buta yang menderita kebutaan total sejak lahir, sedangkan subjek penelitian orang normal dipilih orang yang tidak menderita kelainan mata (tidak memakai kacamata) dan usia yang dipilih adalah orang yang sudah berhenti proses pertumbuhan.

Jenis ras memperlihatkan perbedaan yang lebih besar dalam segala variasi daripada jenis ke$\operatorname{lamin}^{15}$. Perbedaan kelompok etnik manusia mempunyai kecenderungan memperlihatkan pola bentuk tengkorak dan rahang, meskipun pola tersebut sering tidak terlihat oleh karena adanya variasi individual ${ }^{14}$. Faktor genetik memegang peranan utama dan faktor lingkungan hanya sebagai penunjang ${ }^{16}$. Berdasarkan hal tersebut, maka dalam seleksi subjek penelitian dipilih orang Indonesia keturunan Jawa sedikitnya dua generasi di atasnya.

Inklinasi maksila (hubungan maksila terhadap basis kranial anterior) antara kelompok buta dan normal baik pada subjek laki-laki maupun perempuan menunjukkan terdapat perbedaan yang tidak bermakna (Tabel 1 dan 2). Hasil ini tidak mendukung pernyataan bahwa perbedaan utama morfologi kraniofasial antara orang buta dan normal kemungkinan disebabkan oleh penyimpangan pertumbuhan dan perkembangan daerah orbital pada subjek buta yang menyebabkan penurunan inklinasi maksila, tetapi mendukung pernyataan bahwa perbandingan angular antara laki-laki dan perempuan tidak menunjukkan adanya perbedaan ${ }^{4,5}$.

Inklinasi mandibula meliputi pengukuran: a. relasi basis mandibula terhadap basis kranial anterior (NSL/ML); b. relasi ramus mandibula terhadap basis kranial anterior (NSL/RL); dan c. relasi ramus mandibula terhadap maksila (NL/RL). Inklinasi mandibula antara kelompok buta dan normal baik pada subjek laki-laki maupun perempuan menunjukkan terdapat perbedaan yang tidak bermakna (Tabel 1 dan 2). Hasil ini mendukung pernyataan bahwa: a. Besar sudut kranioservikal (NSLOPT) pada subjek buta dan normal masih dalam rentang normal $\left(79^{\circ}\right.$ $\left.-113^{\circ}\right)$, sehingga tidak mempengaruhi inklinasi mandibula ${ }^{6}$; b. Sudut kranioservikal (NSL/OPT) lebih kecil dari $79^{\circ}$, akan menyebabkan penurunan pergeseran sendi temporomandibular ke belakang, peningkatan prognatisme mandibula dan maksila serta rotasi mandibula ke depan lebih besar, apabila sudut kranioservikal (NSL/OPT) lebih besar dari $113^{\circ}$, akan menyebabkan peningkatan pergeseran sendi temporomandibular ke belakang penurunan prognatisme mandibula dan maksila serta terjadi penurunan rotasi mandibula ke depan ${ }^{12}$; c. Perbandingan angular antara laki-laki dan perempuan tidak menunjukkan perbedaan ${ }^{4,5}$.

Ukuran maksila yang meliputi: a. Panjang basis maksila (ss - pm) dan b. Panjang maksila (sppm). Panjang basis maksila pada kelompok buta 
antara laki-laki dan perempuan dan pada kelompok normal antara laki-laki dan perempuan menunjukkan perbedaan yang bermakna (Tabel 2). Ukuran maksila antara kelompok laki-laki buta dan perempuan normal menunjukkan adanya perbedaan yang bermakna (Tabel 2). Hasil ini mendukung pernyataan bahwa semua ukuran liniar menunjukkan laki-laki lebih besar daripada perempuan ${ }^{4}$.

Ukuran mandibula meliputi: a. Panjang mandibula (pgn - cd); b. panjang basis mandibula (pg - tgo); dan bentuk mandibula (ML/RL). Panjang mandibula dan panjang basis mandibula laki-laki normal lebih besar daripada perempuan normal dan kelompok buta (Tabel 2). Panjang basis mandibula pada kelompok perempuan buta lebih kecil daripada perempuan normal (Tabel 2). Hasil ini mendukung pernyataan bahwa: ukuran liniar laki-laki lebih besar daripada perempuan ${ }^{4}$; dan pada orang buta terjadi gangguan pertumbuhan dan perkembangan di daerah orbita, yang secara tidak langsung akan mempengaruhi pertumbuhan maksila dan mandibula ${ }^{5}$.

Rerata bentuk mandibula (sudut mandibular) antara kelompok buta dan normal baik pada laki-laki maupun perempuan menunjukkan perbedaan yang tidak bermakna (Tabel 2). Hasil ini tidak mendukung pernyataan bahwa postur kepala akan mempengaruhi morfologi kraniofasial dan dentoalveolar antara lain: mempengaruhi tinggi dentoalveolar anterior, inklinasi bidang oklusal pada kasus dengan defisiensi keseimbangan dentoalveolar dan overbite, mempengaruhi posisi mandibula, sudut mandibular dan inklinasi insisif bawah ${ }^{8-11}$. Tetapi hasil ini mendukung pernyataan bahwa Perbandingan angular antara laki-laki dan perempuan tidak menunjukkan perbedaan ${ }^{4,5}$.

Pengaruh postur kepala terhadap morfologi kraniofasial dan dentoalveolar pada subjek buta antara lain: tinggi muka anterior atas lebih kecil pada subjek laki-laki buta daripada normal, terjadi penambahan hubungan vertikal rahang, terjadi penambahan sudut mandibular, terjadi penurunan inklinasi insisif bawah, terjadi retrognatisme mandibular, terjadi penambahan inklinasi mandibula, terjadi penurunan inklinasi maksila dan penurunan ukuran maksila ${ }^{4.5}$.

\section{KESIMPULAN}

Berdasarkan penelitian yang telah dilakukan, maka dapat disimpulkan bahwa:

1. Tidak terdapat perbedaan inklinasi maksila, inklinasi mandibula, dan bentuk mandibula antara kelompok buta dan normal.

2. Panjang basis maksila laki-laki lebih besar daripada perempuan baik pada kelompok buta maupun normal.
3. Ukuran maksila laki-laki buta lebih besar daripada perempuan normal.

4. Panjang mandibula dan panjang basis mandibula laki-laki normal lebih besar daripada perempuan normal dan kelompok buta.

5. Panjang mandibula dan panjang basis mandibula pada kelompok perempuan buta lebih kecil daripada kelompok perempuan normal.

\section{DAFTAR PUSTAKA}

1. Supono A: Indera orang buta, Yogyakarta: Kumpulan Makalah Simposium Kebutaan, Fakultas Kedokteran Universitas Gadjah Mada 1983.

2. Sasraningrat $\mathrm{FH}$ : Validasi dan revalidasi penyandang tunanetra. Panduan antara pengalaman pribadi dan ilmu pengetahuan, Yogyakarta : Kumpulan Makalah Simposium Kebutaan, Fakultas Kedokteran Universitas Gadjah Mada, 1983.

3. Vig PS, Showfety KJ, \& Phillips C: Experimental manipulation of head posture, Am J Orthod 1980; 77:25868.

4. Fjellvang $\mathrm{H}$, \& Solow B: Craniocervical postural relations and craniofacial morphology in 30 blind subjects, Am J Orthod Dentofac Orthop 1986; 90: 327-34.

5. Dogan S, \& Erturk N: The effect of vision on craniocervical posture and its relation to craniofacial and dentoalveolar morphology, Quint Int 1990; 21: 401-6.

6. Christnawati: Perbandingan postur kepala antara orang buta dan orang berpenglihatan normal. Kajian sefalometri radiografik terhadap subjek dewasa di Daerah Istimewa Yogyakarta, Tesis, Surabaya: Universitas Airlangga, 1993.

7. Cole SS: Natural head position, posture and prognatism, Br J Orthod 1988; 52: 283-99.

8. Solow, B, Siersbaek-Nielsen S, \& Greve E: Airway adequacy and head posture, and craniofacial morphology, Am J Orthod 1984; 86: 214-23.

9. Solow B, \& Tallgren A: Head posture and craniofacial morphology, Am J Phys Anthrop 1976; 44: 417-36.

10. Solow B, \& Tallgren A: Dentoalveolar morphology in relation to craniocervical posture, Angle Orthod 1977; 47: 157-64.

11. Marcotte MR: Head posture and dentofacial proportions, Angle Orthod 1981; 51: 208-13.

12. Solow, B, \& Siersbaek-Nielsen S: Growth change in head posture related to craniofacial development, $\mathrm{Am}$ J Orthod 1996; 89: 132-40.

13. Fisher CA: Racial, cultural and historical bases of Indonesian regionalism. In South East Asia: A social, economic and political geography, London: Methuen \& Co. Ltd, 1964; 239-63.

14. Foster TD: A text book of orthodontics, Oxford: Blackwell Scientific Pub 1975: 1-43.

15. Aoki H, Fukuyama T, Mita, \& Ukiya M: A morphologycal study and comparison on the dental arch form Japenese and American adults, a preliminary report, bull tokyo Dent Coll 1970; 1: 201-10.

16. Lavelle CLB: A study of craniofacial form, Angle Orthod 1979; 49: 65-71. 